\title{
Using Monte Carlo Simulation for Pro Forma Financial Statements
}

\author{
Michael Crum \\ Northern Michigan University \\ Charles Rayhorn \\ Northern Michigan University
}

This paper discusses the usefulness of Monte Carlo simulation and the ease in which it can be incorporated into upper-level undergraduate business courses. While this technique is not typically covered in detail in undergraduate business textbooks, the availability of software that can perform Monte Carlo simulation means that it can be easily covered and demonstrated in the classroom. This paper also includes an example problem in which Monte Carlo simulation is used to forecast financial statements and determine additional funds needed (AFN) for a small business. This problem can be used by faculty to demonstrate this technique in the classroom or as a student assignment.

Keywords: Additional Funds Needed, Monte Carlo Simulation, Financial Statements

\section{INTRODUCTION}

Monte Carlo simulation refers to a computerized mathematical technique that provides a range of possible outcomes and their probabilities of occurrence, given specific input ranges and probabilities (Albright \& Winston, 2014). According to Harrison (2010), "This form of simulation was first developed and used systematically during the Manhattan Project, the American World War II effort to develop nuclear weapons. John von Neumann and Stanislaw Ulam suggested it for investigating properties of neutron travel through radiation shielding and named the method after the Monte Carlo Casino in Monaco. They, along with others, used simulation for many other nuclear weapon problems and established most of the fundamental methods of Monte Carlo simulation" (Harrison, 2010; p. 2). Monte Carlo simulation has found use in other domains since then, including project management (Kwak \& Ingall, 2007), finance (Amédée-Manesme et al., 2013; Boyle et al., 1997), natural resource extraction (Ungerer et al., 2005), renewable energy (Monforti et al., 2014) and agriculture (Joyce \& Hobson, 2007). Many business problems involve decision making in contexts in which inputs are part deterministic and part random (i.e., not fixed), and better described by a probability distribution. In such cases, deterministic mathematical modeling of outputs are likely inappropriate or impractical (Harrison, 2010), and Monte Carlo simulation is increasingly the methodology used to solve these types of problems.

The purpose of this paper is to demonstrate the usefulness and relative ease of incorporating Monte Carlo simulation into undergraduate capstone business courses, including those in accounting, finance, management, and entrepreneurship. First, this paper discusses the rationale for and ease with which Monte Carlo simulation can be incorporated into college-level business courses. Secondly, a simple 
example problem is presented that demonstrates the use of Monte Carlo simulation. While this paper is aimed at faculty who teach business courses, we hope that more widespread use of Monte Carlo simulation in the classroom will motivate students to apply simulation when they are evaluating projects after they graduate to the 'real' world.

\section{THE CASE FOR USING MONTE CARLO SIMULATION IN THE CLASSROOM}

There are many decisions made by businesses in the face of substantial uncertainty ${ }^{1}$. However, there is not much evidence that uncertainty is considered in a formal quantitative way when making decisions in smaller businesses. For example, financial projections are commonly part of a business plan for starting a new business as well as the financial statements prepared for the owners of existing businesses. Seldom do you see in these plans and financial statements a sensitivity or scenario analyses, let alone more advanced Monte Carlo simulations. Likewise, commonly used textbooks on the topic of entrepreneurship and business planning typically do not include a discussion of Monte Carlo simulation when discussing making financial projections (Kuratko, 2016; Mariotti \& Glackin, 2014) ${ }^{2}$. Furthermore, most beginning corporate finance textbooks only provide a brief description of simulation. Thus, despite the uncertainty associated with financial projections, most business students do not receive the skills needed to use quantitative techniques for examining risk, such as Monte Carlo simulation.

It is beyond the scope of this paper to prove why the modeling of risk is not as widely taught as it should be, but it probably is due in large part to the perceived difficulty of teaching it and the assumed lack of student ability to comprehend the subject. There are easy to use, but expensive, simulation software packages such as @Risk $(>\$ 2,000)$, Crystal Ball $(\sim \$ 1,000)$, and ModelRisk (full version $>\$ 750)$ that do Monte Carlo simulation. The widespread use of these packages will happen over time as many management science, and advanced corporate finance textbooks come bundled with semester access for student versions of @Risk and Crystal Ball. But interested faculty do not have to wait for student versions of these programs to become available. There are several free and powerful simulation programs now available that do Monte Carlo simulation, such as Ersatz ${ }^{3}$ and the basic and free version of ModelRisk ${ }^{4}$. However, even when using these programs, some knowledge of spreadsheet modeling and basic probability and statistics is necessary. An excellent resource for reviewing basic probability and statistics concepts is the website of Robert Nau at the Fuqua School of Business (Nau, 2019).

The next section of this paper presents a case appropriate for use in most junior or senior level accounting, finance, entrepreneurship, or other business capstone courses where financial statement analysis and forecasting are required.

\section{A SMALL BUSINESS EXAMPLE OF MONTE CARLO SIMULATION: DETERMINING ADDITIONAL FUNDS NEEDED (AFN) AT THE PORT CHARLOTTE BIKE SHOP}

Using a Monte Carlo simulation in developing pro forma financial statements is instructive for several reasons. Firstly, pro forma financial statements show the effects that expected revenue and expenses have on the expected profitability of the business to be examined. They are typically constructed using a percentage of sales method. Using Monte Carlo simulation allows for a more robust analysis of the potential risk associated with each variable. Secondly, pro forma financial statements often serve as a tool to determine at what point the firm will burn through all their cash, and additional funding will need to be raised to sustain the business. However, estimating the point that additional funds will be needed requires some unknown inputs, such as the expected cash inflows and outflows for the period.

The assignment requires students to develop 2018 and 2019 pro forma financial statements and determine the additional funds needed to balance the balance sheets for each year. Initially, we ignore the uncertainty regarding some of the forecasted values given in the case. Once students finish these point estimate financial statements and AFN projections, they are asked to develop a Monte Carlo simulation to estimate net income and additional funds needed. 
To do a simulation, one of the first, and probably the most critical decision, is what probability distribution to use. For large businesses, long runs of financial data are available from which an educated guess can be made about which distribution to use for a given variable. For small businesses or startups, this information is not available, or if it is, the collection period is too short, and an educated guess is difficult. In cases like this, where the distribution is unknown, the triangle distribution can be used. All that is needed is a low, middle (most likely), and a high estimate for each input variable. The triangle distribution is an extension of the classical scenario analysis that appears in all beginning corporate finance and some entrepreneurship textbooks. Furthermore, it is an intuitive and flexible choice for Monte Carlo simulations. This distribution can be symmetrical or skewed depending on the parameters specified. All inputs in the example are assumed to follow a triangle distribution.

\section{Part 1: The Data and Creation of Point Estimate Pro Forma Financial Statements to Determine Additional Funds Needed (AFN) at the Port Charlotte Bike Shop}

Port Charlotte Bike Shop is a retail bike store in Port Charlotte, Florida ${ }^{5}$. The bike shop has been operating since 2006 when it opened to meet the growing demand for bikes in Port Charlotte. Doug Daniels, the owner of Port Charlotte Bike Shop, started the business in 2006. For the first two years of operation, the shop did very well. However, after the collapse of the real estate market in 2008 and 2009, sales dropped dramatically, and Doug laid off all of his employees except himself and one other part-time employee. Since then, the local economy has improved dramatically, and 2017 was a moderately profitable year (see the 2017 financial statements in Table 1).

Doug believes that the improving economy may warrant an expansion of the bike shop. After some preliminary legwork, Doug thinks that he will have to move to a new location, which he can rent for $\$ 24,000$ per year with an annual utility charge of $\$ 10,000$ (compared to the rent and utilities on the old building which will remain the same for 2018 as for the previous year). If he decides to expand, he will start leasing the new building at the beginning of December of 2018 and be in the new facility by the end of the month. Thus, he will be paying rent and utilities for both locations during December 2018 . Marketing and administrative expenses are expected to go up to $\$ 14,000$ in 2018 and $\$ 14,500$ in 2019 to make sure that customers are informed about the new location. Furthermore, if he proceeds with this project, depreciation expense is expected to increase to $\$ 3,850$ in 2018 and $\$ 6,835$ in 2019 . Other expenses will remain the same percentage of total revenue in 2018 and 2019 that they were in 2017.

Doug believes that 2018 sales will be similar to 2017 sales since the expansion will not yet have taken place. He expects that bike sales will grow by 5\% compared to 2017 . He expects accessory sales and service revenue to be $15 \%$ and $28 \%$ of bike sales respectively, which is similar to what has occurred in the past. For 2019, Doug expects bike sales to grow by 10\% over the 2018 sales amount. Since the new location will be able to carry more accessories and offer more complete bike repair services, he expects accessory sales and service revenue to go up to $18 \%$ and $33 \%$ of bike sales respectively. Cost of goods sold in 2017 is $74.2 \%$ for bikes, $59.3 \%$ for accessories, and $30.5 \%$ for service (service cost of goods sold includes only parts, not labor). Doug expects these percentages to be the same for 2018 and 2019. The income of the bike shop is taxed at $25 \%$.

With the expansion, he will need to acquire some additional long-term assets during the last half of 2018 , such as bike racks, furniture, and equipment/tools. The estimated cost is assumed to be $\$ 32,500$. No additional long-term assets will be needed for 2019. With more floor space, he will need an additional inventory of $\$ 35,000$ in 2018 , and $\$ 31,000$ in 2019. This purchase should be reflected on the balance sheet by increasing year-end inventory by these amounts, respectively. He also wants to maintain a cash balance of 4\% of total sales for 2018 and 2019. Luckily, Doug has a good relationship with his suppliers (he always pays on time) and will be able to take advantage of vendor financing. Thus, he expects accounts payable for 2018-19 to remain the same percentage of sales as in 2017. Likewise, he expects accruals to have the same percentage of total sales for 2018 and 2019 as in 2017. Doug retained all of the earnings from 2017 into the business to help fund the expansion and is willing to do the same in 2018 and 2019. However, he believes the internally generated retained earnings will not be sufficient to fund the 
expansion, and that additional money will need to be borrowed from a bank, contributed by an investor, or self-financed.

TABLE 1

2017 PORT CHARLOTTE BIKE SHOP FINANCIAL STATEMENTS

\begin{tabular}{|c|c|c|c|}
\hline Income Statement & 2017 & Balance Sheet & 2017 \\
\hline Bike Sales & $\$ 325,452$ & Current Assets & \\
\hline Accessory Sales & $\$ 45,632$ & Cash & $\$ 15,400$ \\
\hline Service Revenue & $\$ 87,522$ & Inventory & $\$ 118,520$ \\
\hline \multirow[t]{2}{*}{ Total Revenue } & $\$ 458,606$ & Total Current Assets & $\$ 133,920$ \\
\hline & & Capital (Long-Term) Assets & $\$ 35,124$ \\
\hline Cost of Goods Sold & $\$ 295,239$ & Minus Accumulated Depreciation & $\$ 11,250$ \\
\hline Gross Profit & $\$ 163,367$ & Total Assets & $\$ 157,794$ \\
\hline Rent & $\$ 13,947$ & & \\
\hline Utilities & $\$ 7,500$ & Current Liabilities: & \\
\hline Wages & $\$ 86,522$ & Accounts Payable & $\$ 32,484$ \\
\hline Marketing \& & & & \\
\hline Administrative & $\$ 5,410$ & Accruals & $\$ 3,546$ \\
\hline Depreciation & $\$ 3,400$ & Current Liabilities & $\$ 36,030$ \\
\hline Other & $\$ 3,544$ & Long-Term Debt & $\$ 0$ \\
\hline EBIT & $\$ 43,044$ & Owner's Equity & $\$ 121,764$ \\
\hline Interest & $\$ 0$ & & \\
\hline EBT & $\$ 43,044$ & & \\
\hline Taxes & $\$ 10,761$ & & \\
\hline Net Income & $\$ 32,283$ & & \\
\hline
\end{tabular}

With the above information, students should create income statement and balance sheet projections for 2018 and 2019 using a point estimate. Once they complete these statements, the instructor should discuss with students what problems they encountered. (The instructor will then discuss the scenario analysis approach. An optional and intermediate assignment would have the students use a high, low, and expected sales estimate and rework the pro forma financial statements.)

This discussion should be followed by one or two classroom periods demonstrating a Monte Carlo simulation program after which the students will continue with Part 2 of the case.

\section{Part 2: Using Monte Carlo Simulation to Develop Pro Forma Financial Statements and to Determine Additional Funds Needed (AFN) at the Port Charlotte Bike Shop}

Doug realizes that even though estimating additional funds needed by projecting the income statement and the balance sheet is more accurate than simply estimating it using the AFN formula, his estimate may nevertheless be inaccurate. There are many values estimated in the projected financial statements which may turn out not to be true, which could influence the actual additional funds needed. Doug is particularly worried about 2018 since a substantial amount of cash will be going out to fund the expansion, but the additional revenue the expansion is projected to bring in will not occur until 2019. While many of his estimates could be wrong, he is particularly worried about the growth rate he projected for bike sales in 2018 and 2019. Likewise, he is unsure about sales in the accessory and service areas, as well as labor and other expenses. 
TABLE 2

SIMULATION INPUTS- ESTIMATED DISTRIBUTION PARAMETERS

\begin{tabular}{|lrr|}
\hline Bikes Sales Growth & $\mathbf{2 0 1 8}$ & $\mathbf{2 0 1 9}$ \\
Most Likely & $5.00 \%$ & $11.67 \%$ \\
Min & $-10.00 \%$ & $-3.33 \%$ \\
Max & $25.00 \%$ & $31.67 \%$ \\
Accessory Sales \% of Bike Sales & $\mathbf{2 0 1 8}$ & $\mathbf{2 0 1 9}$ \\
Most Likely & $15.00 \%$ & $18.00 \%$ \\
Min & $13.00 \%$ & $16.00 \%$ \\
Max & $19.00 \%$ & $22.00 \%$ \\
Service Revenue \% of Bike Sales & $\mathbf{2 0 1 8}$ & $\mathbf{2 0 1 9}$ \\
Most Likely & $28.00 \%$ & $33.00 \%$ \\
Min & $25.00 \%$ & $30.00 \%$ \\
Max & $34.00 \%$ & $39.00 \%$ \\
Wages \% of Total Sales & $\mathbf{2 0 1 8}$ & $\mathbf{2 0 1 9}$ \\
Most Likely & $18.87 \%$ & $18.87 \%$ \\
Min & $16.87 \%$ & $16.87 \%$ \\
Max & $20.87 \%$ & $20.87 \%$ \\
Other Expenses \% of Total Sales & $\mathbf{2 0 1 8}$ & $\mathbf{2 0 1 9}$ \\
Most Likely & $0.77 \%$ & $0.77 \%$ \\
Min & $0.67 \%$ & $0.67 \%$ \\
Max & $0.87 \%$ & $0.87 \%$ \\
Accounts Payable \% of Total Sales & $\mathbf{2 0 1 8}$ & $\mathbf{2 0 1 9}$ \\
Most Likely & $7.08 \%$ & $7.08 \%$ \\
Min & $6.08 \%$ & $6.08 \%$ \\
Max & $10.08 \%$ & $10.08 \%$ \\
\hline
\end{tabular}

Given all this uncertainty, Doug pulls out some notes from his capstone business course he had a decade ago. After reviewing these, he realizes that some of the inputs, such as bike sales growth, accessory sales as a percentage of bike sales, service revenue as a percentage of bike sales, and accounts payable should have a right-skewed triangle distribution reflecting the upside potential these inputs should have. Upon further reflection, he determines that wages and other expenses should follow a symmetrical triangle distribution since they are usually a percentage of total sales. For 2019, bike sales growth should be dependent on how things will turn out in 2018. Table 3 is a summary of his revised expectations. Note that bike sales growth is the percentage growth from the previous year's bike sales, while accessory sales and service revenue are estimated percentages of the current year's bike sales. Wages, other expenses, and accounts payable are estimated percentages of total sales for the current year. 
TABLE 3

2018 AND 2019 PRO FORMA FINANCIAL STATEMENTS USING THE MODIFIED PERCENTAGE OF SALES APPROACH

\begin{tabular}{|c|c|c|c|c|c|c|}
\hline \multicolumn{2}{|c|}{ Port Charlotte Bike Shop Income Statement } & \multirow[t]{2}{*}{ Growth Rate } & \multirow{2}{*}{$\begin{array}{c}5.0 \% \\
2018 \mathrm{e}\end{array}$} & \multicolumn{3}{|c|}{$10.0 \%$} \\
\hline & 2017 & & & & $\underline{2019 e}$ & \multirow{18}{*}{ 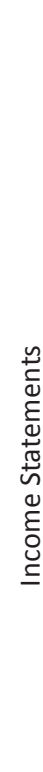 } \\
\hline Bike Sales & $\$ 325,452$ & & $\$ 341,725$ & & $\$ 375,897$ & \\
\hline Accessory Sales & $\$ 45,632$ & $15.0 \%$ & $\$ 51,259$ & $18.0 \%$ & $\$ 67,661$ & \\
\hline Service Revenue & $\$ 87,522$ & $28.0 \%$ & $\$ 95,683$ & $33.0 \%$ & $\$ 124,046$ & \\
\hline Total Revenue & $\$ 458,606$ & & $\$ 488,666$ & & $\$ 567,605$ & \\
\hline Cost of Goods Sold & $\$ 295,239$ & & $\$ 313,139$ & & $\$ 356,873$ & \\
\hline Gross Profit & $\$ 163,367$ & & $\$ 175,527$ & & $\$ 210,732$ & \\
\hline Rent \& Utilities & $\$ 13,947$ & & $\$ 15,947$ & & $\$ 24,000$ & \\
\hline Utilities & $\$ 7,500$ & & $\$ 8,333$ & & $\$ 10,000$ & \\
\hline Wages & $\$ 86,522$ & & $\$ 92,193$ & & $\$ 107,086$ & \\
\hline Marketing \& Administrative & $\$ 5,410$ & & $\$ 14,000$ & & $\$ 14,500$ & \\
\hline Depreciation & $\$ 3,400$ & & $\$ 3,850$ & & $\$ 6,835$ & \\
\hline Other & $\$ 3,544$ & & $\$ 3,776$ & & $\$ 4,386$ & \\
\hline EBIT & $\$ 43,044$ & & $\$ 37,427$ & & $\$ 43,924$ & \\
\hline Interest & $\$ 0$ & & $\$ 0$ & & $\$ 0$ & \\
\hline EBT & $\$ 43,044$ & & $\$ 37,427$ & & $\$ 43,924$ & \\
\hline Taxes (25\%) & $\$ 10,761$ & & $\$ 9,357$ & & $\$ 10,981$ & \\
\hline Net Income & $\$ 32,283$ & & $\$ 28,070$ & & $\$ 32,943$ & \\
\hline \multicolumn{6}{|l|}{ Balance Sheet Data } & \\
\hline Current Assets & & $\Delta 18$ & & $\Delta 19$ & & \multirow{15}{*}{ 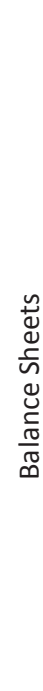 } \\
\hline Cash & $\$ 15,400$ & & $\$ 19,547$ & & $\$ 22,704$ & \\
\hline Inventory & $\$ 118,520$ & $\$ 35,000$ & $\$ 153,520$ & $\$ 31,000$ & $\$ 184,520$ & \\
\hline Total Current Assets & $\$ 133,920$ & \multirow{3}{*}{$\$ 32,500$} & $\$ 173,067$ & \multirow{3}{*}{$\$ 0$} & $\$ 207,224$ & \\
\hline Capital (Long-Term) Assets & $\$ 35,124$ & & $\$ 67,624$ & & $\$ 67,624$ & \\
\hline Minus Accum Dep & $\$ 11,250$ & & $\$ 15,100$ & & $\$ 21,935$ & \\
\hline Total Assets & $\$ 157,794$ & & $\$ 225,591$ & & $\$ 252,913$ & \\
\hline Current Liabilities: & & & & & & \\
\hline Accounts Payable & $\$ 32,484$ & & $\$ 34,613$ & & $\$ 40,205$ & \\
\hline Accruals & $\$ 3,546$ & & $\$ 3,778$ & & $\$ 4,389$ & \\
\hline Current Liabilities & $\$ 36,030$ & & $\$ 38,392$ & & $\$ 44,593$ & \\
\hline Long-Term Debt & $\$ 0$ & & $\$ 0$ & & $\$ 0$ & \\
\hline Owner's Equity & $\$ 121,764$ & & $\$ 149,834$ & & $\$ 220,142$ & \\
\hline Equity Needed & $\$ 121,764$ & & $\$ 187,199$ & & $\$ 208,320$ & \\
\hline AFN & $\$ 0$ & & $\$ 37,365$ & & $-\$ 11,822$ & \\
\hline
\end{tabular}

The following are a set of questions (optional) to guide students in solving this case for both Part 1 and Part 2.

Part 1

You will be using Excel for all your calculations. Make sure that you use cell referencing - do not do fixed, or one time, calculations. If you do fixed calculations, you will not be able to simulate your financial statements in Part 2 of this assignment. 
A. Given the data provided in this case, calculate the percentage of sales for each item in the 2017 financial statements (these ratios will be used in the percentage of sales calculations).

B. Using your answer for part 1A, prepare the pro forma income statements and balance sheets for 2018 and 2019. Use the modified percentage of sales method. The modifications are stated by Doug Daniels in the case narrative.

C. Calculate the additional funds needed using the difference between equity needed and the forecasted owner's equity on your balance sheets. Are the differences positive, negative, or zero?

D. Interpret your results, discussing what they imply for the Port Charlotte Bike Shop expansion project.

Part 2

Copy your pro forma statements from Part 1 and place them into a new worksheet in the same workbook. Run a Monte Carlo simulation for 2018 and 2019 with the following variables as uncertain inputs into the simulation: bike sales growth, accessory sales as a percentage of bike sales, service revenue as a percentage of bike sales, wages as a percentage of total sales, other expenses as a percentage of total sales, and accounts payable as a percentage of total sales. Use the triangle distribution using the most likely, minimum, and maximum distribution values provided in Table 2. Additional funds needed and net income should be selected as your output variables. Simulate with at least 1000 iterations.

A. Based on the simulation results, what is the expected value (mean) of additional funds needed?

B. Discuss if additional funds are likely to be needed, and what variability is present. If relevant, discuss what financing sources might make sense for the Port Charlotte Bike Shop given these results.

\section{Model Output and Interpretation}

Table 3 contains the solution for Part 1 . AFN is $\$ 37,365$ for 2018 . It is $-\$ 11,822$ for 2019 , indicating no additional funds will be needed for 2019.

For Part 2, the simulation is ran using both Ersatz and ModelRisk for 1,000 iterations (note that with Monte Carlo simulation, results may vary slightly from simulation run to simulation run). Table 4 contains the spreadsheet developed to run the simulations. Table 5 contains summary statistics of the output variables obtained from simulating in both Ersatz and ModelRisk. Mean AFN for 2018 was found to be $\$ 30,547$, and $\$ 30,481$ with the simulations ran in Ersatz and ModelRisk respectively. Standard deviations of $\$ 8,280$ and $\$ 8,157$ were obtained. Mean AFN for 2019 was found to be $-\$ 17,029$ and $\$ 16,084$ with the simulations ran in Ersatz and ModelRisk respectively. While this would indicate that Doug could expect that no additional funds will be needed in 2019, the standard deviation and confidence interval should be examined as well. For example, the $95 \%$ confidence interval ranges from $-\$ 50,428$ to $\$ 10,466$ for the 2019 AFN output variable. While additional funds will likely not be needed in 2019 , there is a non-trivial possibility that some additional funds will be needed. 
TABLE 4

2018 AND 2019 PRO FORMA FINANCIAL STATEMENTS USING THE MODIFIED PERCENTAGE OF SALES APPROACH SIMULATING THE SHADED VARIABLES

\begin{tabular}{|c|c|c|c|c|c|c|c|c|}
\hline \multicolumn{9}{|c|}{ Port Charlotte Bike Shop Income Statement } \\
\hline & 2018e & 2019e & & 2018 & 2019 & & $\underline{2018}$ & 2019 \\
\hline & & & Bikes Sales Growth & $10.70 \%$ & $7.76 \%$ & Wages $\%$ of Total Sales & $18.66 \%$ & $18.75 \%$ \\
\hline Bike Sales & $\$ 360,273$ & $\$ 388,229$ & Most Likely & $5.00 \%$ & $15.70 \%$ & Most Likely & $18.87 \%$ & $18.87 \%$ \\
\hline Accessory Sales & $\$ 54,471$ & $\$ 69,647$ & Min & $-10.00 \%$ & $0.70 \%$ & Min & $16.87 \%$ & $16.87 \%$ \\
\hline Service Revenue & $\$ 101,747$ & $\$ 122,842$ & Max & $25.00 \%$ & $35.70 \%$ & Max & $20.87 \%$ & $20.87 \%$ \\
\hline \multirow{2}{*}{ Total Revenue } & $\$ 516,492$ & $\$ 580,717$ & Accessory Sales \% of Bike Sales & $15.12 \%$ & $17.94 \%$ & Other $\%$ of Total Sales & $0.82 \%$ & $0.75 \%$ \\
\hline & & & Most Likely & $15.00 \%$ & $18.00 \%$ & Most Likely & $0.77 \%$ & $0.77 \%$ \\
\hline Cost of Goods Sold & $\$ 330,657$ & $\$ 366,833$ & Min & $13.00 \%$ & $16.00 \%$ & Min & $0.67 \%$ & $0.67 \%$ \\
\hline Gross Profit & $\$ 185,835$ & $\$ 213,884$ & Max & $19.00 \%$ & $22.00 \%$ & Max & $0.87 \%$ & $0.87 \%$ \\
\hline Rent & $\$ 15,947$ & $\$ 24,000$ & Service Revenue $\%$ of Bike Sales & $28.24 \%$ & $31.64 \%$ & AP $\%$ of Total Sales & $8.15 \%$ & $8.01 \%$ \\
\hline Utilities & $\$ 8,333$ & $\$ 10,000$ & Most Likely & $28.00 \%$ & $33.00 \%$ & Most Likely & $7.08 \%$ & $7.08 \%$ \\
\hline Wages & $\$ 96,356$ & $\$ 108,913$ & Min & $25.00 \%$ & $30.00 \%$ & Min & $6.08 \%$ & $6.08 \%$ \\
\hline Marketing \& Administrative & $\$ 14,000$ & $\$ 14,500$ & Max & $34.00 \%$ & $39.00 \%$ & Max & $10.08 \%$ & $10.08 \%$ \\
\hline Depreciation & $\$ 3,850$ & $\$ 6,835$ & & & & & & \\
\hline Other & $\$ 4,257$ & $\$ 4,340$ & & 2018 & 2019 & & & \\
\hline EBIT & $\$ 43,091$ & $\$ 45,297$ & Bikes Sales Growth & $10.70 \%$ & $7.76 \%$ & & & \\
\hline Interest & $\$ 0$ & $\$ 0$ & Accessory Sales \% of Bike Sales & $15.12 \%$ & $17.94 \%$ & & & \\
\hline EBT & $\$ 43,091$ & $\$ 45,297$ & Service Revenue \% of Bike Sales & $28.24 \%$ & $31.64 \%$ & & & \\
\hline Taxes & $\$ 10,773$ & $\$ 11,324$ & Wages $\%$ of Total Sales & $18.66 \%$ & $18.75 \%$ & & & \\
\hline \multirow[t]{2}{*}{ Net Income } & $\$ 32,318$ & $\$ 33,973$ & Other $\%$ of Total Sales & $0.82 \%$ & $0.75 \%$ & & & \\
\hline & & & AP $\%$ of Total Sales & $8.15 \%$ & $8.01 \%$ & & & \\
\hline \multirow[t]{2}{*}{ Balance Sheet Data } & & & & 2018 & 2019 & & & \\
\hline & & & Bike Sales & $\$ 360,273$ & $\$ 388,229$ & & & \\
\hline Current Assets & & & Accessory Sales & $\$ 54,471$ & $\$ 69,647$ & & & \\
\hline Cash & $\$ 20,660$ & $\$ 23,229$ & Service Revenue & $\$ 101,747$ & $\$ 122,842$ & & & \\
\hline Inventory & $\$ 153,520$ & $\$ 184,520$ & Total Revenue & $\$ 516,492$ & $\$ 580,717$ & & & \\
\hline Total Current Assets & $\$ 174,180$ & $\$ 207,749$ & Net Income & $\$ 32,318$ & $\$ 33,973$ & & & \\
\hline Capital (Long-Term) Assets & $\$ 67,624$ & $\$ 67,624$ & AFN & $\$ 26,559$ & $-\$ 12,196$ & & & \\
\hline Minus Accumulated Deprecia & $\$ 15,100$ & $\$ 21,935$ & & & & & & \\
\hline Total Assets & $\$ 226,704$ & $\$ 253,438$ & & & & & & \\
\hline \multicolumn{9}{|l|}{ Current Liabilities: } \\
\hline Accounts Payable & $\$ 42,069$ & $\$ 46,530$ & & & & & & \\
\hline Accruals & $\$ 3,994$ & $\$ 4,490$ & & & & & & \\
\hline Current Liabilities & $\$ 46,063$ & $\$ 51,020$ & & & & & & \\
\hline Long-Term Debt & 0 & 0 & & & & & & \\
\hline Owner's Equity & $\$ 154,082$ & $\$ 214,613$ & & & & & & \\
\hline Equity Needed & $\$ 180,641$ & $\$ 202,417$ & & & & & & \\
\hline AFN & $\$ 26,559$ & $-\$ 12,196$ & & & & & & \\
\hline
\end{tabular}

In Figure 1, the left column contains the histograms for the output variables total revenue, net income, and AFN obtained from the simulation ran in Ersatz for 2018. The right three histograms are from the simulation performed in ModelRisk for the same year and in the same order. Figure 2 shows the histograms of the same outputs for 2019. Note that they are similar, and are consistent with the summary statistics output in Table 5 . 
FIGURE 1

HISTOGRAMS OF SIMULATION OUTPUT VARIABLES FOR 2018

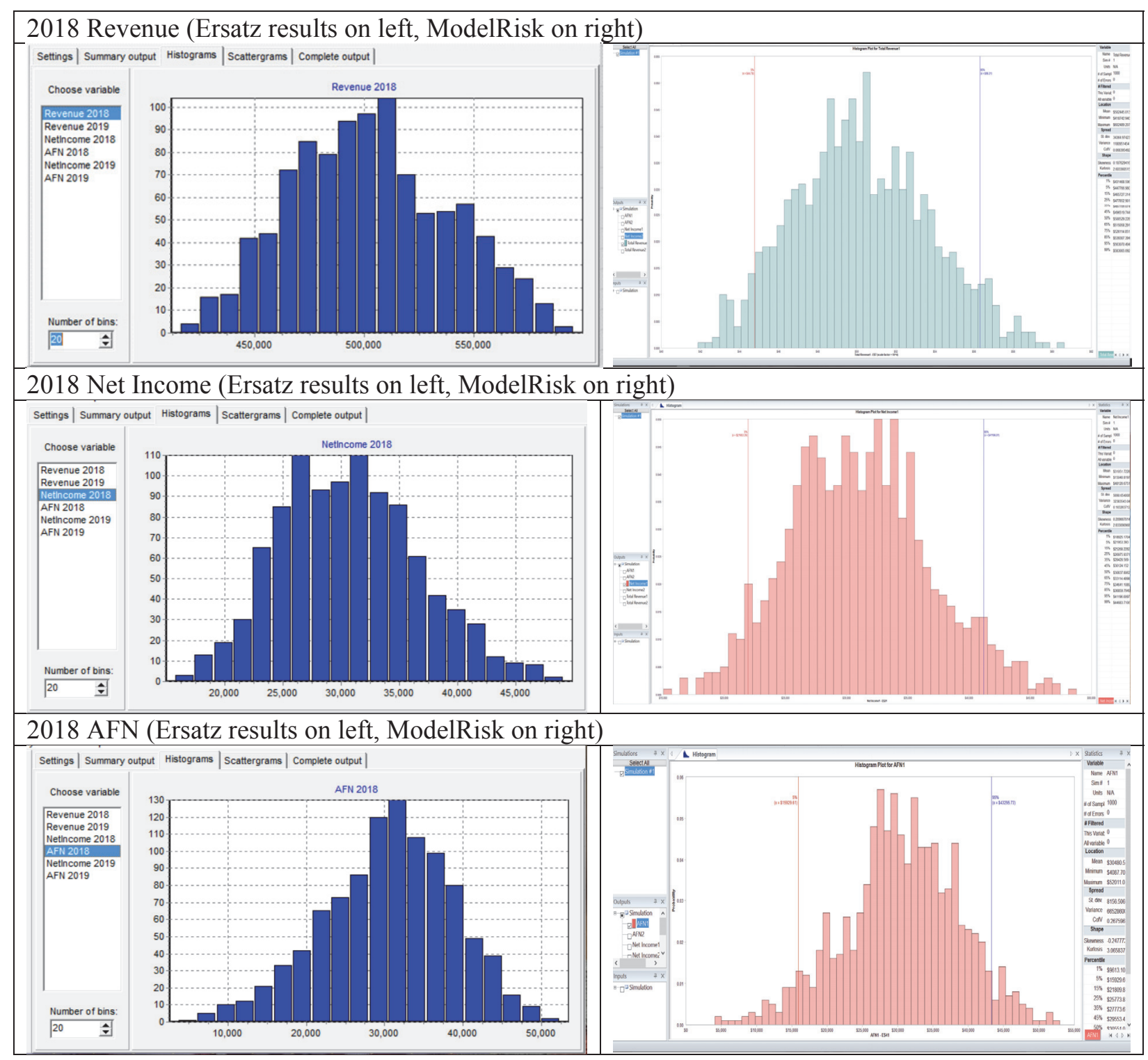


FIGURE 2

HISTOGRAMS OF SIMULATION OUTPUT VARIABLES FOR 2019

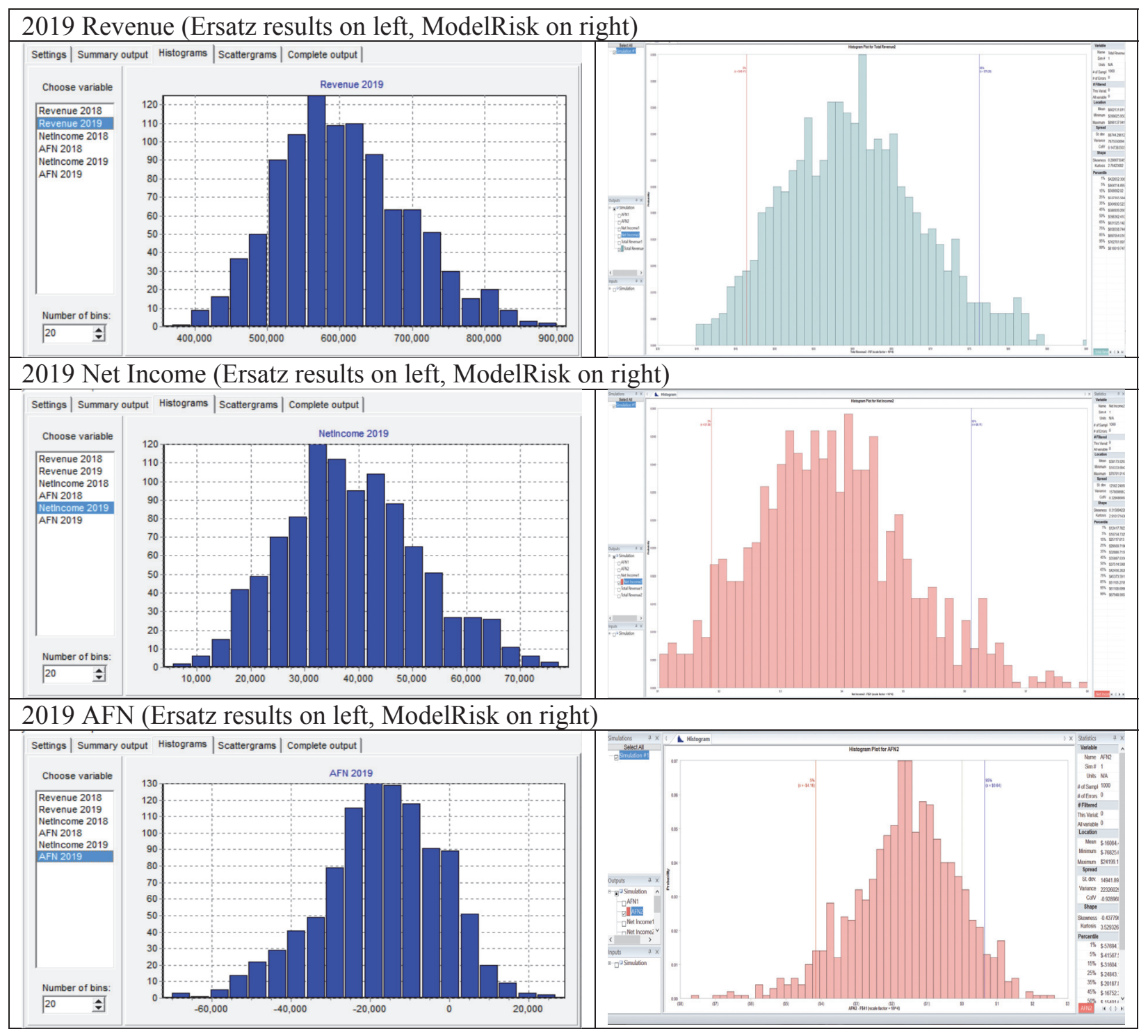


TABLE 5

SIMULATION RESULTS- SUMMARY STATISTICS

\begin{tabular}{|c|c|c|c|c|c|c|c|}
\hline \multicolumn{8}{|c|}{ Panel A: Summary Statistics for Ersatz } \\
\hline Variable & Median & Mean & Low & High & StDev & LCI 95\% & HCI 95\% \\
\hline Revenue 2018 & $\$ 500,932.38$ & $\$ 502,845.85$ & $\$ 416,163.60$ & $\$ 595,833.68$ & $\$ 35,954.79$ & $\$ 437,133.39$ & $\$ 574,891.91$ \\
\hline Revenue 2019 & $\$ 597,974.98$ & $\$ 605,385.89$ & $\$ 368,277.73$ & $\$ 900,661.54$ & $\$ 90,710.19$ & $\$ 443,869.99$ & $\$ 804,627.57$ \\
\hline NetIncome 2018 & $\$ 30,488.55$ & $\$ 30,728.48$ & $\$ 15,742.96$ & $\$ 49,080.40$ & $\$ 5,982.11$ & $\$ 20,081.37$ & $\$ 43,131.19$ \\
\hline NetIncome 2019 & $\$ 37,877.88$ & $\$ 38,860.95$ & $\$ 5,451.25$ & $\$ 77,291.24$ & $\$ 12,769.73$ & $\$ 16,458.41$ & $\$ 64,984.62$ \\
\hline AFN 2018 & $\$ 31,128.07$ & $\$ 30,547.10$ & $\$ 3,662.89$ & $\$ 52,364.04$ & $\$ 8,280.30$ & $\$ 12,440.76$ & $\$ 45,299.93$ \\
\hline AFN 2019 & $-\$ 16,215.13$ & $-\$ 17,028.64$ & $-\$ 70,191.47$ & $\$ 26,988.09$ & $\$ 15,263.62$ & $-\$ 50,427.63$ & $\$ 10,465.56$ \\
\hline \multicolumn{8}{|c|}{ Panel B: Summary Statistics for ModelRisk } \\
\hline Variable & Median & Mean & Low & High & St.Dev. & LCI $95 \%$ & HCI 95\% \\
\hline Revenue 2018 & $\mathrm{n} / \mathrm{a}$ & $\$ 502,445.01$ & $\$ 418,742.94$ & $\$ 602,489.21$ & $\$ 34,364.97$ & $\mathrm{n} / \mathrm{a}$ & $\mathrm{n} / \mathrm{a}$ \\
\hline Revenue 2019 & $\mathrm{n} / \mathrm{a}$ & $\$ 602,131.81$ & $\$ 399,025.95$ & $\$ 896,137.94$ & $\$ 88,744.30$ & $\mathrm{n} / \mathrm{a}$ & $\mathrm{n} / \mathrm{a}$ \\
\hline NetIncome 2018 & $\mathrm{n} / \mathrm{a}$ & $\$ 31,051.72$ & $\$ 15,040.82$ & $\$ 48,120.68$ & $\$ 5,690.65$ & $\mathrm{n} / \mathrm{a}$ & $\mathrm{n} / \mathrm{a}$ \\
\hline NetIncome 2019 & $\mathrm{n} / \mathrm{a}$ & $\$ 38,173.02$ & $\$ 10,333.68$ & $\$ 78,701.01$ & $\$ 12,562.24$ & $\mathrm{n} / \mathrm{a}$ & $\mathrm{n} / \mathrm{a}$ \\
\hline AFN 2018 & $\mathrm{n} / \mathrm{a}$ & $\$ 30,480.59$ & $\$ 4,087.71$ & $\$ 52,011.02$ & $\$ 8,156.51$ & $\mathrm{n} / \mathrm{a}$ & $\mathrm{n} / \mathrm{a}$ \\
\hline AFN 2019 & $\mathrm{n} / \mathrm{a}$ & $-\$ 16,084.40$ & $-\$ 76,825.68$ & $\$ 24,199.11$ & $\$ 14,941.90$ & $\mathrm{n} / \mathrm{a}$ & $\mathrm{n} / \mathrm{a}$ \\
\hline
\end{tabular}

\section{CONCLUSION}

Teaching students why we use and how to use Monte Carlo simulation in forecasting financial statements is important. Point forecasts of these statements do not show the variable nature of the future. Scenario analysis takes a step in the right direction but is limited to a limited number of discrete outcomes. Monte Carlo analysis paints a much more complete picture. It is true this picture may not be true because of our assumptions about the data distributions, the likely lack of data to estimate the distribution, not fully understanding correlations between the data, and so on. However, this will likely be true with any method that is chosen. The most important reason, in our opinion, why simulations need to be taught in the classroom is to help future decision makers. Doing the analysis will force people to consider the multitude of issues that need to be addressed in running a business. Such pondering will, in the long run, lead to better decisions being made.

\section{ENDNOTES}

1. A distinction is sometimes made between risk and uncertainty, such as by Knight (1921). However, we do not make a distinction between these two terms in this paper.

2. An exception being Smith, Smith, \& Bliss (2011), which is an entrepreneurial finance textbook that does cover Monte Carlo simulation.

3. Available at: http://www.epigear.com/index_files/ersatz.html

4. Available at: https://www.vosesoftware.com/products/modelrisk/

5. This narrative is fictional. 


\section{REFERENCES}

Albright, S., \& Winston, W. (2014). Business analytics: Data analysis and decision making. Cengage Learning.

Amédée-Manesme, C.O., Barthélémy, F., Baroni, M., \& Dupuy, E. (2013). Combining Monte Carlo simulations and options to manage the risk of real estate portfolios. Journal of Property Investment \& Finance, 31(4), 360-389.

Boyle, P., Broadie, M., \& Glasserman, P. (1997). Monte Carlo methods for security pricing. Journal of economic dynamics and control, 21(8-9), 1267-1321.

Harrison, R. L. (2010). Introduction to Monte Carlo simulation. In AIP Conference Proceedings (pp. 1721). American Institute of Physics.

Joyce, J. A., \& Hobson, P. A. (2007). Monte Carlo simulation as a tool for technical modeling and project analysis. In Proceedings of the International Society of Sugar Cane Technologists (pp. 12181227). International Society of Sugar Cane Technologists.

Knight, F. H., (1921). Risk, uncertainty, and profit. New York, NY: Hart, Schaffner, and Marx.

Kuratko, D. F., (2016). Entrepreneurship: Theory, process, and practice. Cengage Learning.

Kwak, Y. H., \& Ingall, L. (2007). Exploring Monte Carlo simulation applications for project management. Risk Management, 9(1), 44-57.

Mariotti, S., \& Glackin, C., (2014). Entrepreneurship \& small business management. Pearson Education.

Monforti, F., Huld, T., Bódis, K., Vitali, L., D'isidoro, M., \& Lacal-Arántegui, R. (2014). Assessing complementarity of wind and solar resources for energy production in Italy. A Monte Carlo approach. Renewable Energy, 63, 576-586.

Nau, R. (2019) Statistical forecasting: Notes on regression and time series analysis. Duke University. Retrieved from https://people.duke.edu/ rnau/411home.htm

Smith, J., Smith, R. L., \& Bliss, R. (2011). Entrepreneurial finance: strategy, valuation, and deal structure. Stanford University Press.

Ungerer, P., Tavitian, B., \& Boutin, A. (2005). Applications of molecular simulation in the oil and gas industry: Monte Carlo methods. Paris, France: Editions Technip. 